\title{
On the life of rhinos: Written into the simple stars
}

Leave them quiet repose

beside their place of thorn

dung and dragon fly

allow them still shade beneath

the flame-blown trees

whilst spiders, beetles, worms and tortoises

spin, bore, creep, explore...

let their rock-ribbed outlines old as the world

be one with its rugged rim and wide ridged ranges allow them to forklift a wall of turf

tread apart the clods

plough beyond the frontiers

to wade in waters where coronets of lily weed cap the brows of drowsing hippos

let their eyes gleam yellow as they dream over pools reflecting fever trees, algae and mimosa permit! for rhino eyes have over the aeons mirrored trellis works of track-forged trails

where migratory hordes encoded

to creep the earth's seams

find their way to warmth

midst thorn, hook and barb

grant that their ductile hides and vulnerable horns remain whole and unhurt

let the descending star-shoots fill the streams

where the herds gather

and phosphorescent waters

dribble from their muzzles as they slurp

enable a night pricked to life by African ardour its innominate stars like beams glanced off knife tips to describe a trapezium over the huddle

of heads, backs and hinds of a hundred rhinos.

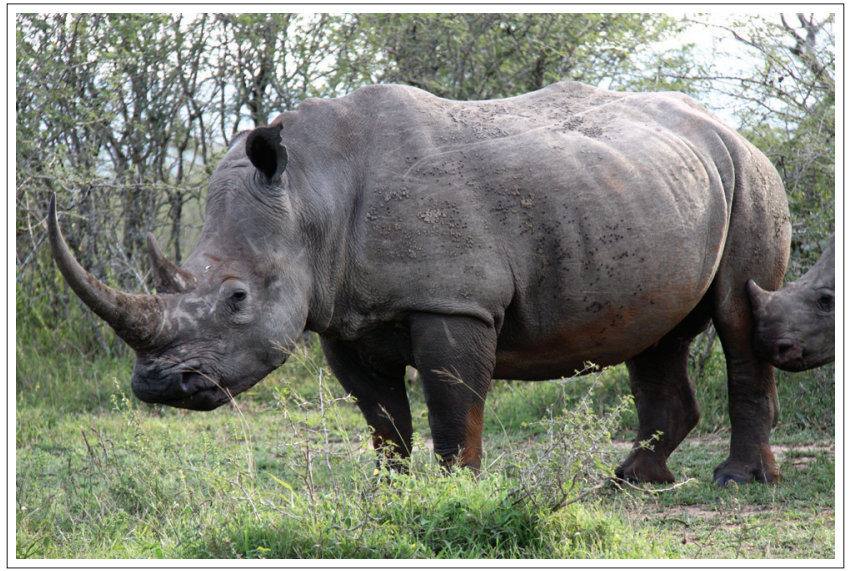

Source: This picture is used with the permission of the author, Patricia G. Maritz 